\title{
Prácticas de Lectura» Ámbitos Privados y Formación de un Espacio Público Moderno
}

Renán Silva*

* Historiador, Decano de la Facultad de Ciencias Sociales y Económicas e Investigador del CIDSE 


\section{RESUMEN}

Sobre la base del examen documentado de un caso histórico ejemplar, el autor demuestra que las relaciones entre lo público y lo privado no son un problema de espacialidad física, sino un ámbitoflexible determinado por las prácticas sociales, las que dotan de un carácter público o privado a un conjunto de espacios, siempre en proceso de redefinición. En el presente caso el autor señala cómo la práctica de la lectura puede fiindar lo público en el espacio mismo de la convivialidady la amistad.

Las prácticas de la lectura parecen haber conocido modificaciones importantes en la segunda mitad del siglo XVIII en el virreinato de Nueva Granada. Estas modificaciones, que cubren aspectos variados, parecen orientarse en su conjunto a producir una nueva relación con los textos, pero no menos parecen haber sido uno de los elementos centrales del cambio en las relaciones entre lo público y lo privado, así como de la aparición de un espacio público moderno, paradójicamente constituido en sus fases iniciales en el ámbito de lo privado. Las fortalezas y las debilidades de este espacio se conocerán en Nueva Granada después de 1808 , en el momento en que comienza de manera abierta a plantearse el problema de la política moderna, con su característica apelación a la opinión pública'.

Tres aspectos, que se encuentran ligados, parecen ser lo más destacado de estas modificaciones. En primer lugar la creación en medios urbanos de asociaciones en el marco de las cuales la lectura llegó a ocupar un papel central. En segundo lugar la creación de algunas redes de lectores en el campo, entre antiguos universitarios que ejercían su profesión

1 Las orientaciones teóricas generales en: Habermas, Jurgen, Historia y Critica de la opinión pública [1962]. Barcelona, Gustavo Gili, 1981; Cochin Agustín, Les sociétés de pensée et la démocratie moderne. Etudes d'histoire révolutionnaire. París, Copernic, 1978. Aries, Philippe y Dubby, Georges (bajo la dirección de). Historia de la vida privada. El proceso de cambio en la sociedad del siglo XVI a la sociedad del siglo XVIII. 5. -Volumen dirigido por $\mathrm{R}$, Chartier [1985]. Madrid, Taurus, 1987. Chartier, Roger (bajo la dirección de), Practiques de la lecture París, Petite Bibliotheque Payot, Segunda edición, 1993 de abogados, pero que en ocasiones eran también propietarios de haciendas. $\mathrm{Y}$ en tercer lugar el nuevo interés que se conoce por la lectura de las gacetas, interés que cubría un espectro social que empezaba a ser de alguna amplitud, como se comprobará después de 1808 cuando, en medio de la crisis revolucionaria, se verá aumentar el flujo de este tipo de impreso, el que junto con la folletería, será la forma básica de circulación de las ideas políticas, por lo menos hasta la mitad del nuevo siglo.

El carácter minoritario de los grupos sociales afectados en principio por estas nuevas prácticas de la lectura, por las formas de relación y de asociación que suponían, no debe hacer perder de vista su novedad y significación, pues ése es el marco en el que empezaba por primera vez a fabricarse una sociedad de opinión y de libre examen, a la manera de un laboratorio que resultó central cuando la crisis desatada por la invasión napoleónica en España abrió el problema de la representación del Reino y terminó por transformar a los miembros de la República de las Letras en los hombres de la palabray de la pluma, es decir, en los formadores y los representantes de la opinión. Son esos pasos iniciales de un proceso reducido en principio a los miembros de la nueva élite cultural, los que nos proponemos examinar aquí.

\section{Asociaciones para la Lectura}

A finales del siglo XVIII, por lo menos en Santafé, uno de los lugares principales de 


\section{Son las prácticas sociales y los actores en el acontecimiento, os que dotan de un cierto carácter público o privado a un conjunto de espacios.}

reunión de la juventud universitaria estaba constituido por las tertulias. Se trata de espacios privados o semi-privados - a aún espacios públicos utiíizados de manera privada- de conversación y discusión que funcionaban en las habitaciones de los estudiantes en los colegios, en casas de particulares y, por lo menos en un caso, en la Biblioteca Pública.

Las relaciones entre lo público y lo privado deben detener un momento nuestra atención, por lo menos para señalar que ninguna espacialidad física -y ni siquiera institucionalse encuentra de por sí de uno u otro lado de una frontera que, por lo demás, es siempre móvil. Son las prácticas sociales y los actores en el acontecimiento, los que dotan de un cierto carácter público o privado a un conjunto de espacios. Así por ejemplo, la actividad de la tertulia que se reunía en la Biblioteca Pública de Santafé, tenía un carácter privado, no solo porque el contenido concreto de sus reuniones se hurtaba a la vigilancia y control de las autoridades, sino principalmente porque los sujetos se congregaban en tanto particulares para expresar de manera libre sus puntos de vista y opinión. Lo mismo ocurría en el Observatorio Astronómico y en la llamada Casa de la Botánica, que funcionaron como centros de reunión y de discusión de individuos que habían decidido educarse por su cuenta, al margen de las instituciones oficiales del saber (los Colegios-universidades).
En sentido contrario, los ámbitos familiares y los lugares de convivialidad (amistad, conversación, paseo campestre, caminata urbana, regocijo), que existían con anterioridad a la transformación que sobre ellos induce la actividad Ilustrada, son espacios más domésticos que privados en el sentido moderno de la expresión; tradicionalmente estaban rodeados de una sociabilidad amplia, anónima y desprendida de toda perspectiva cultural de autoeducación, de lecturas y de libre examen de distintas opiniones. Los cambios producto de la práctica ilustrada de la comunicación cultural tienden a separar el elemento "público" (de circulación amplia y difusa) del ámbito familiar y simplemente "domestico", al introducir en el intercambio la exigencia del uso de la razón entre individuos teóricamente iguales. Tal uso se manifiesta en la conversación conducida por la lectura y en el examen de un conjunto argumentativo que confronta al mismo tiempo la palabra del libro y aquello que empieza a ser observado -y considerado digno de observación- y que los Ilustrados llamarán la "realidad"

Pero las tertulias no fueron ni una creación original ni un hecho exclusivo de Santafé. En realidad se trataba de una modalidad de encuentro que recogía elementos de las formas más tradicionales de la sociabilidadhispánica: la visita de conversación y de cumplimiento, y la reunión más o menos espontánea

2 Las relaciones entre lo doméstico, lo privado y lo público como espacios de socialización en el pensamiento y en las prácticas ilustradas son un problema complejo desconocido para la historiografía colombiana. Un ejemplo de tal complejidad se puede encontrar en la actividad de Camilo Torres, quien en una primera fase de su vida, siendo soltero y catedrático, reside en el Colegio del Rosario, en donde lee y atiende a sus estudiantes en su habitación; mientras que en una segunda fase ya casado y ejerciendo siempre como docente, recibe en su casa estudiantes universitarios que vienen de la Gobernación de Popayán, a los que alquila habitaciones para mejorar sus finanzas y por pedido de sus padres y acudientes, pero los que no dejan de intercambiar culturalmente con su maestro, usar su biblioteca y formar tertulia en la casa de Torres. 
de amigos de similares condiciones sociales para pasar "unas horas de diversión", sin que en principio la "utilidad" formara parte de los objetivos. Algunos ecos de la existencia en la Nueva Granada de esas formas de reunión tradicionales se perciben cuando la aparición del Papel Periódico de Santafé. Lectores de provincia informaron en varias ocasiones, en cartas a su director, sobre la acogida que en las tertulias encontraba el periódico recién fundado, el que parecía constituir la gran novedad de la conversación ${ }^{3}$.

El Papel Periódico daba cuenta también del contenido de muchas de las discusiones que se adelantaban en las tertulias, por lo menos para el caso de Santafé. Se trata de discusiones que, en su conjunto, tienen dos características en común: comienzan a incluir de manera habitual la lectura de libros, y enfrentan puntos de vista diferentes que tratan de dirimir a través del examen de las distintas opiniones de los asistentes. No importa aquí que el tema de la discusión resulte casi siempre convencional ("la belleza sublime") o en ocasiones anodino (las mejores formas de ganarse la lotería) o que encontremos dificultad para precisar el sentido de muchas de esas conversaciones (cuando se conocen sus temas). Podemos acudir a un ejemplo preciso para tratar de ilustrar la situación.

En el Correo Curioso por su parte publicó un artículo en que se describe el ambiente de conversación distendida y de juego que rodeaba una reunión de tertulia, en casa de particulares: "Estaba en buena tertulia y chá-

3 Cfr por e]. Papel Periódico de la ciudad de Santafé de Bogotá, No. 27, 12-VIII-1791. El editor apuntaba: "pero el dolor es que un solo ejemplar suele servir a más de cien personas, si acaso no es auna tercera parte de la ciudad", en lo que debe haber por lo menos exageración, aunque señala el interés por la lectura de la nueva publicación. El comentario general en Silva, R., Prensa y Revolución, Bogotá, Banco de la República, 1988.

4 Correo Curioso Económico y Mercantil de la ciudad deSantafé deBogotá, No. 8, 7-IV-1801.

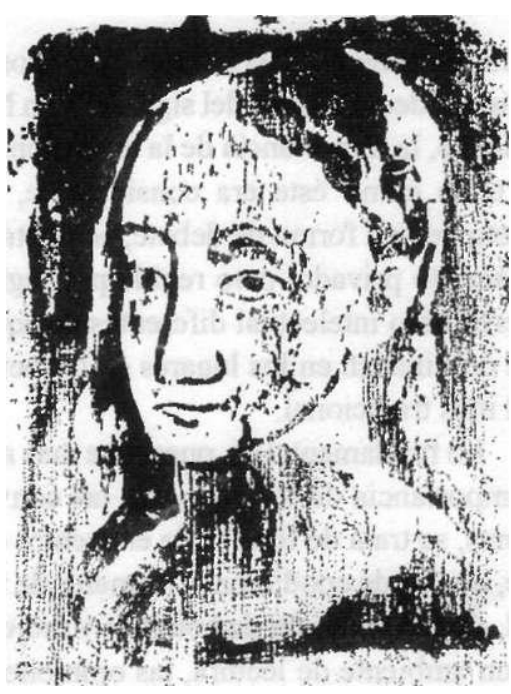

Pablo Picasso: Cabeza de mujer. Grabado en 1906, impreso en 1933

chara un viejo... una mujer... un letrado de profesión... y una dama... Hablaban sobre cosas indiferentes y disputaban sobre una jugada". Pero de un momento a otro hace su irrupción un joven, quien "traía en la mano un papel impreso", el que una de las damas solicita, y empieza entonces la lectura colectiva: "y empezó a leer el Prospecto [del Correo Curioso]", aunque con interrupciones y bromas de los asistentes, los que escucharon y fueron manifestando en tono informal sus opiniones, "hasta que llegó [la lectora] a aquella proposición del dinero guardado ", momento en el cual uno de los asistentes señaló:

"Señores, este papel es el parto de algunos hambrientos que no saben cómo atrapar la plata; y para los que tenemos un decente pasar la abandonemos a sus garras, nos vienen a comulgar con ruedas de molino..."

Lo que se recrea en esta escena imaginaria es, pues, la reacción de una parte de la sociedad ante un tema fundamental: el ideal de la prosperidad, expresado a través de la idea de que el dinero debe circular (una de las propuestas del Correo Curioso y de los Ilus- 
trados en general). Así pues, en términos de la sociedad de principios del siglo XIX en Nueva Granada, la importancia de la discusión sobre un tema como éste era considerable, y era objeto de una forma de debate, adelantada en un ámbito privado, pero regida por reglas de intercambio intelectual diferentes de aquellas que dominaban en los lugares de la sociabilidad más tradicional.

Lo fundamental es, pues, que más allá de la importancia de los temas de las conversaciones, se trata de formas de encuentro en las que, dentro de condiciones formales de igualdad, de participación de hombres y mujeres, y en un ambiente de lectura, las opiniones empiezan a confrontarse, y en ocasiones a mostrar puntos de apoyo argumentativo inéditos, como el testimonio, la observación y la medida, como si las condiciones de verdad de un juicio y las maneras de someterlo a prueba se estuvieran alterando.

\section{Las Tertulias de Lecturas}

Un hecho significativo es el de la modificación que parecen haber conocido algunas tertulias sobre la base de su encuentro con la lectura, con intereses intelectuales ahora dotados de mayor complejidad, y con formas de discusión y de crítica de mayores exigencias ${ }^{5}$, sobre temas como aquellos de la búsqueda de la prosperidad, la utilidad y la virtud. En términos estrictos se puede afirmar que las "tertulias", aunque se tratara de formas de sociabilidad tradicionales, permitieron la expresión de los nuevos ideales e intereses culturales que se manifestaban principalmente, en el caso de Nueva Granada, en el mundo universitario, resultando al parecer una especie de forma híbrida penetrada ya por elemen-

5 Correo Curioso Económico y Mercantil de la ciudad de Santafé de Bogotá, No. 8, 7-IV-1801.

6 Cf. Sobre este punto, pero en relación con el conjunto de Hispanoamérica. Guerra, Francois-Xavier,Moafernidad e Independencias, Madrid, Mapfre, 1992, pp 86-113, particularmente pp. 92-98.

\section{las "tertulias"permitieron la expresión de los nuevos ideales $e$ intereses culturales resultando al parecer una especie de forma híbrida penetrada ya por elementos del modelo de organización de las modernas academias de ciencias y sociedades de literatos conocidas en otras latitudes}

tos del modelo de organización de las modernas academias de ciencias y sociedades de literatos conocidas en otras latitudes, aunque siempre acompañadas por elementos de la sociabilidad más tradicional. Esas "reuniones" y "asociaciones" resultaron no sólo un vehículo para la circulación del nuevo libro y de nuevas prácticas de lectura, sino uno de los puntos centrales de formación de prácticas sociales modernas respecto de la libre elección, la manifestación de juicios, la construcción de una opinión, elementos todos que distinguen un espacio público moderno

La Tertulia Eutropélica, que animó en Santafé, en los años 1790 el bibliotecario y el director del Papel Periódico Manuel del Socorro Rodríguez, es una buena muestra de todo lo anterior:

"Tratándose una noche en la Tertulia Eutropélica varios puntos de amena literatura, ya por mero pasatiempo, o con el laudable interés de la reciproca ilustración de todos, se tocó casualmente esta cuestión [si quien fija reglas poéticas, puede equivocarse en el uso de ellas], con el motivo de haberse leído cierto libro ". 
A continuación de su informe, Rodríguez describe un ambiente de participación colectiva ("con mucho calor y variedad se discurrió sobre la materia"), de expresión de distintas opiniones ("sosteniendo cada uno su dicta$\left.m e n^{\prime \prime}\right)$, con apoyo en los textos de los humanistas clásicos (pues se discutió "con no poco aparato de argumentos y de citas"), hasta añadir: "Qué escrutinio tan general se hizo de sus obras" [de Horacio y de Cicerón]'. Según la narración de Rodríguez, un verdadero experto en retórica, "la tempestad erudita" duró un poco más de media hora, hasta que puso las cosas en calma "un respetable socio", quien "captando primero la venia de toda la tertulia, habló en estos términos...", y comienza entonces la narración del contenido mismo de la discusión.

No se trata aquí simplemente de las "tertulias" como formas espontáneas de conversación y de discusión (las "tertulias y corrillos"), sino de asociaciones literarias con una mínima estructuración, producto de la introducción de algunas reglas de debate, de la fijación de cierta periodicidad para sus reuniones, y que incluían de manera explícita como uno de sus objetivos, la educación recíproca de sus miembros. ${ }^{8}$ Estos elemento mínimos de es-

7 Papel periódico, No. 125, 17-Y-1794. El subrayado es mío.

8 En otro momento Rodríguez dará como definición de esta tertulia la siguiente: "Como el fin de todos los individuos que componen esta asamblea de honesta diversión, es discurrir sobre cuantos asuntos tengan conexión con la amena literatura y otros objetos de isntracción...". Papel Periódico, No. 154, 8-VIII1794.

9 "Habiéndose dado por asunto para la noche del viernes 12 de octubre...", Papel Periódico No. 153, 1-VIII1794.

10 ídem. El subrayado es mió.

11 La definición de ese ideal de la libre comunicación cultural aparecerá con claridad en el Prospecto del Correo Curioso, en la presentación de sus tareas. "Es bien conocida la utilidad de los medios que facilitan la mutua comunicación de las ideas para la consecución de las ilustraciones de los hombres y el engrandecimiento de un Estado", Correo Curioso, No. 1, 17-11-1801.

\section{Más allá de los elementos tradicionales que todavía permanecen en estas nuevas sociedades de lectura y discusión, cabe preguntarse cuál fue su extensión en el caso de Nueva Granada, pues su carácter minoritario parece confirmado}

tructuración de una sociedad literaria, que va más allá de las habituales tertulias de conversación, aparece manifiesto en otro informe de Rodríguez: los socios -es la palabra que él utiliza- habían determinado como tema para la reunión, "un rasgo de elocuencia en elogio del incomparable Cristóbal Colón, con motivo de cumplirse los trescientos años del descubrimiento de América.' El "erudito socio" cumplió con su tarea, y concluyó "con una profunda reverencia a toda la asamblea", luego de lo cual ("terminado que fue este acto académi$\left.c o^{\prime \prime}\right)$, los asistentes solicitaron a una "socia poetisa" la glosa de un dístico, "con la advertencia de que reuniese estos tres elogios: de Dios, de los Reyes y del Almirante"10.

Estamos pues frente a un proceso de transformación, mediado por la práctica de la lectura, la discusión y la libertad crítica. Este proceso conduce de las formas tradicionales de tertulia hacia formas nuevas de la comunicación cultural, aun conformes con la cultura política de esa sociedad y rodeadas todavía de una gruesa capa retórica, pero que introduce prácticas y estilos que en parte corresponden ya a los de una asociación moderna de contenido igualitario y de libre exposición de las ideas ${ }^{11}$.

Más allá de los elementos tradicionales que todavía permanecen en estas nuevas so- 
ciedades de lectura y discusión, cabe preguntarse cuál fue su extensión en el caso de Nueva Granada, pues su carácter minoritario parece un hecho confirmado. Es por ejemplo notable que la correspondencia de los naturalistas de la Gobernación de Popayán nunca mencione este tipo de asociaciones literarias, como no se mencionan sino tardíamente para Cartagena de Indias, y, por lo que conocemos, en ningún para la ciudad de Mompox ni para la provincia de Antioquia'2. En Santa Fe existía la mencionada Tertulia Eutropélica, que tiempo después funcionará en la Biblioteca Pública como Asamblea del Buen Gusto, y el Salón de reuniones de la aristócrata santafereña y aficionada a las ciencias naturales, doña Manuela Santamaría de Manrique -que era tanto un lugar de conversación como de lectura, tanto de intriga palaciega como de libre intercambio de opiniones-. Fuera de ello parecen no quedar sino las reuniones de lectura y discusión en casas de particulares, y la actividad de lectura y aprendizaje en la Casa de la Botánica, y en el Observatorio Astronómico, después de 1804, año en que Francisco José de Caldas se convirtiera en su director .

Muchos testimonios de contemporáneos, entre ellos el de José Manuel Restrepo, han informado sobre las reuniones que se adelantaban en el Observatorio Astronómico, el que para tres o cuatro universitarios se transformó

\section{Es importante resaltar este hecho de la escasa extensión de las nuevas asociaciones para la lectura -en sentido estricto-, y la consiguiente permanencia de formas tradicionales como las "tertulias"}

en una verdadera academia de estudio de las ciencias naturales, en buena medida porque allí podían disponer de instrumentos científicos, de una biblioteca especializada y de los propios conocimientos de F. J. de Caldas, quien tenía el proyecto de formar a algunos de sus amigos como geógrafos y astrónomos ${ }^{14}$.

Según el inventario que se hizo de los libros e instrumentos del Observatorio Astronómico, este parece relativamente bien dotado para la experimentación, y en todo caso un lugar adecuado para la lectura de libros y publicaciones sobre las ciencias: muchos textos de ciencias de las academias europeas, diarios y memorias de científicos, muchísimas relaciones de viaje, una buena cantidad de libros de historia (de la naturaleza en primer lugar, pero igualmente de las sociedades y de los gobiernos), diccionarios y gramáticas de lenguas extranjeras, "ciento sesenta cuadernos del diario enciclopédico", cerca de doscientos cincuenta mapas, etc. ${ }^{15}$.

Es importante resaltar este hecho de la escasa extensión de las nuevas asociaciones para la lectura -en sentido estricto-, y la consiguiente permanencia de formas tradicionales como las "tertulias". En efecto, lo que parece haber ocurrido en Nueva Granada,

12 En el caso de Mompox un equivalente podría ser la Sociedad Económica de Amigos de País, fundada después de 1780. En Popayán, que sepamos funcionaba un tertulia en los primeros años del siglo XIX. Cf. Hernández de Alba, Guillermo, el doctor José Félix Restrepo y su época, Bogotá, 1969, pp. 140-141.

13 En el siglo XIX, en Santafé, para describir los movimientos de un ilustrado sobre el espacio de la ciudad, se dirá que circula entre la Biblioteca Pública, la Casa de la Botánica, el Observatorio Astronómico, y la casa de Camilo Torres. Cf. Gómez Hoyos, Rafael, $L a$ Revolución neogranadina. Ideario de una generación y de una época, T2, Bogotá, Instituto de Cultura Hispánica, 1982, 0.218 y ss, quien menciona así el movimiento cotidiano de Manuel Pombo a su regreso de España y siendo ya funcionario de la Casa de la Moneda.

14 Cf. Restrepo, J. M., Autobiografía, op. cit, p. 9.

15 Para lo inventarios mencionados cf. Hernández de Alba, Guillermo, Historia documental de la Real Expedición Botánica, Bogotá, Instituto de Cultura Hispánica 1986, pp. 272-279 y pp. 316-327. 
como en otras partes de Hispanoamérica, es que, ante el hecho de las prohibiciones y vigilancias que pesaban sobre toda iniciativa de organización autónoma, los espacios tradicionales hayan debido funcionar como lugares de implantación y desarrollo de formas y prácticas de gran novedad, desde el punto de vista de las "sociabilidades". Por lo demás se trata de formas de encuentro de una gran movilidad y de rápidas transformaciones en cuanto a sus fines, a sus orientaciones, y sobre todo en cuanto a sus prácticas, en la medida en que la política moderna y el periodismo político van haciendo su irrupción. Sin que se pueda desconocer la debilidad del tejido asociativo en el que se pudiera expresar un tipo de práctica cultural que negaba muchos aspectos de la sociedad tradicional, debe afirmarse que reuniones puramente de amigos, y en ocasiones casi de familiares que hacían uso de espacios privados, deben haber funcionado como sustitutos de las organizaciones que se prohibían y de las cuales las autoridades sospechaban, sobre todo después de 1791.

Parece claro que muchas de las tertulias de Nueva Granada, consideradas como reuniones de "amigos literatos", pudieron funcionar, respecto de ciertas metas, como verdaderas sociedades académicas o de pensamiento, con prácticas de discusión libre, de votación, de elección, y con la discusión de proyectos sobre el destino de la sociedad, sobre las posibilidades de una "comunidad imaginada". En el caso de la ciudad de Cartagena, sabemos de la existencia por lo menos de una tertulia, denominada literaria, pero de la cual dependió, hacia 1811-12, la formación de la Sociedad de Amigos del País de esa ciudad, sobre la que desde tiempo atrás se discutía. Según se consigna en el folleto que contiene sus estatu-

16 Cf. Estatutos de la sociedad Económica de Amigos del País... Cartagena, Julio de 1811. En la Imprenta del Real Consulado. 37 p. Biblioteca Nacional, Sala de Investigadores. Las citas en pp. 2-3. tos, la iniciativa de formación de la Sociedad dependió de las "discusiones de tertulia", pues, "habiéndose tratado repetidamente en una tertulia literaria de la ciudad, lo útil que sería establecer una sociedad económica...", luego se procedió por uno de los miembros a la formación de los estatutos, "y los presentó a la tertulia, en donde fueron leídos con general aprobación..." .

Así pues, se trata al parecer de un fenó-

\section{una carencia innegable} de instituciones para

la utopía, que se combina, de otra parte, con una gran riqueza de prácticas dispersas y difusas que se mueven en esa dirección, y que encontraron sus apoyos centrales en el ámbito de lo

\section{privado y en la práctica de la lectura.}

meno de extrema complejidad: de un lado una gran dificultad, que sin duda debe llamarse política, para la organización pública de "sociedades de crítica y de lectura", y de otro lado un cierto desarrollo en el campo de la actividad privada de esas nuevas formas de sociabilidad. O visto desde otro ángulo", de una parte una carencia innegable de instituciones para la utopia, que se combina, de otra parte, con una gran riqueza de prácticas dispersas y difusas que se mueven en esa dirección, y que encontraron sus apoyos centrales en el ámbito de lo privado y en la práctica de la lectura.

\section{Una Sociedad de Lectura en Santafé}

En relación con las asociaciones para la lectura, Santafé conoció una experiencia no- 


\section{"A determinadas horas se juntan (los socios), se leen los papeles, se critica y se conversa sobre aquellos asuntos, de modo que se pueda pasar un par de horas divertidas y con utilidad"}

vedosa, de carácter excepcional, y cortada en sus raíces por las autoridades españolas, aunque ella revestía un carácter privado (sin que su existencia fuera desconocida por las autoridades). Se trata de la "sociedad de literatos" que funcionó en la casa de Antonio Nariño, y de cuya noticia disponemos por las confesiones y testimonios recogidos cuando su juicio por la publicación de Los Derechos del Hombre. Cabe recordar que A. Nariño era comerciante, dueño de una imprenta, prestamista de libros a la mayor parte de sus amigos, a muchos universitarios y a algunas de las autoridades, y era reconocido como "hombre de letras", como aficionado a la lectura. La característica de gran prestamista de libros, en la ciudad y fuera de ella, aparece clara en una lista que se le encontró entre sus papeles, en la cual aparece una parte de sus deudores y los títulos de los libros que tenía en circulación ${ }^{17}$.

Lo importante de tal lista no es, desde luego, solamente el título de algunos de los libros prestados, ni tampoco el número de libros. Lo notable se encuentra más bien del lado de la vasta gama de posiciones sociales que representan quienes tomaban libros en préstamo: clérigos y civiles, altos funcionarios y un simple impresor, abogados y naturalistas, catedráticos y estudiantes. En cierta manera esta lista de préstamo nos habla de una red de lectores que, en parte, describe en términos empíricos la pequeña República de las Letras del Reino, o por lo menos de Santafé18.

Pero las actividades de Nariño iban un poco más allá en cuanto a sus intereses por la lectura, pues se había propuesto la organización, en su casa, de una sociedad de literatos que ya no resulta muy justo denominar "tertulia" -con el significado de simple "reunión de conversación"19-. Entre sus papeles se encontraron algunos apuntes con los nombres de quienes podían participar, al tiempo que un intento de definición de las actividades de la sociedad que se proponía crear:

"Me ocurre el pensamiento de establecer en esta ciudad una suscripción de literatos... esta se reduce a que los suscriptores se juntan en una pieza cómoda, y sacados los gastos de luces, etc., lo restante del dinero se emplea en pedir un ejemplar de los mejores diarios y gacetas extranjeros, los diarios enciclopédicos y demás papeles de esta naturaleza, según la cantidad de la suscripción. A determinadas horas se juntan (los socios), se leen los papeles, se critica y se conversa sobre aquellos asuntos, de modo que se pueda pasar un par de horas divertidas y con utilidad $^{\circ} \quad$ ".

Durante el proceso Nariño intentó negar estas actividades de lectura, que por lo demás eran de conocimiento de muchos en la ciudad, pero se encontró con la sorpresa de que los

17 La lista en Ruis Martínez, Eduardo, La Librería de Nariño y los Derechos del Hombre, Bogotá, Editorial Planeta, 1990, pp. 69-70.

18 Cf. También la lista de los sujetos con quienes dice haber conversado sobre el texto de Los Derechos del Hombre, la que más o menos coincide con la lista de aquellos a quienes prestaba libros. Proceso contra don Antonio Nariño por la publicación clandestina de los Derechos del hombre y del Ciudadano. T.1. Bogotá, Presidencia de la República, 1980, p.119.

19 Nariño utiliza la expresión "una especie de tertulia o junta de amigos de genio, que con el tiempo pudiera ser de utilidad...". CF. Carta del 15-y-1778 de Antonio Nariño para J. C. Mutis, en Archivo Nariño, T.2.. pp. 72-73.

20 Proceso, op. cit, p. 152. El subrayado es mió. 
jueces habían leído con cuidado su correspondencia, encontrando numerosos fragmentos que dejaban en claro los hechos ${ }^{21}$. En el punto preciso de las reuniones de lectura que sostenía en su casa, las que Nariño trató durante el proceso de ocultar a las autoridades, se le citó una parte de una carta del francés Luis de Rieux, en que le decía:

"Si el amigo Zea [Francisco Antonio] hubiese llegado, déle muchas expresiones de mi parte, y manifiéstele el sentimiento que tengo de no poderme encerrar con ustedes en el santuario ${ }^{22 "}$. pues "santuario" era el nombre que daban al lugar de la casa de Nariño en el cual se reunían para leer. Se trataba de un espacio diferenciado, privado, arreglado para los fines precisos de esa actividad y con una particular decoración, cuya descripción se encontró también entre los papeles de Nariño.

Se trata de un plano en que se indica la composición del lugar, adornado con dos estampillas o cuadros de Frankliny de Washington, y sobre la pared colocadas una serie de frases de pensadores, que parecen constituirla biblioteca ideal de los socios del Santuario: Cicerón, William Pitt, Jenofonte, Washington, Tácito, Raynal, Sócrates, Rousseau, Plinio, Buffon, Solón, Montesquieu, Platón, Quintiliano, Franklin y Newton, autores a quienes puede haber leído en algún momento, haber deseado leer, o conocer a través de citas

21 Asi lo prueba una carta de su amigo Cabal: "No me dices si ha venido correo de España, ni me hablas de noticias públicas. Como no estoy suscrito a la gaceta, es preciso que tu la leas con cuidado y me mandes un extracto de lo que válgala pena". Proceso, op. cit, p. 140.

22 Proceso, op. cit, pp. 161-163.

23 J.J. Rousseau, por ejemplo, no figura en la lista de obras secuestradas, aunque Nariño adquirió posteriormente en Europa el Contrato Social. CF. Archivo Nariño, edición de Gonzalo Hernández de Alba. Bogotá, Presidencia de la República, 1990, T.2, pp. 143. Y sin embargo, hay tanto "rousseaunismo" en muchos de sus escritos anteriores!.

24 Cf. Proceso, op. cit., pp. 161-163. de otros autores ${ }^{23}$. Y al parecer la propia decoración del espacio de lectura había sido discutida, por lo menos con algunos de los asistentes, pues, en otra carta, su amigo el naturalista Zea hablará sobre la disposición del lugar, recordará sus preferencias y mostrará su acuerdo con las disposiciones finales de Nari$\sim 24$

no

No es mucho más lo que conocemos sobre la "sociedad de literatos" que Antonio Nariño había constituido en su casa, la que debió suspender sus reuniones en 1794, hecho que significó no sólo un duro golpe para compradores de libros, los lectores que tomaban obras en préstamo y los socios literatos, sino una condenación en bloque para los jóvenes ilustrados, pues en la condena de Nariño, los fiscales de la Real Audiencia extendían su veredicto a todo el grupo.

Tampoco sabemos exactamente desde cuándo venía funcionando la sociedad de lectura, pero, por lo menos el proyecto era anti-

\section{Won cpner colen frozvmzvv}

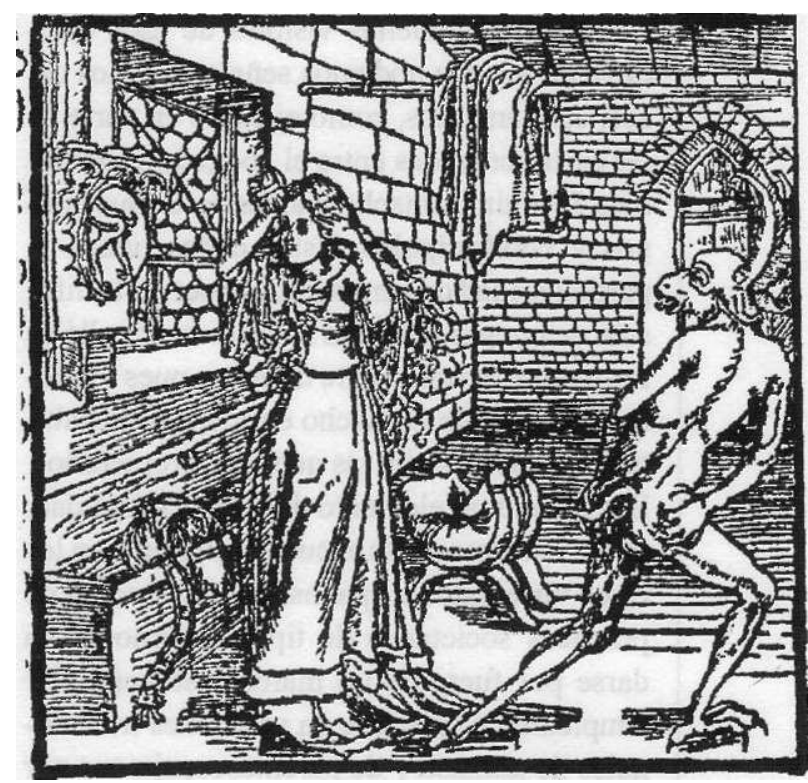

íjne fww»TO«9at mofen $t t £$ fabsg» $\$$ s \& $m i$

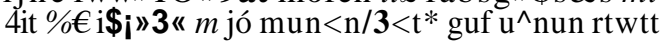

VMtu\&n maXm mit \%«mt tw müsfi^/talfó 
guo, pues cuando su elección como uno de los alcaldes de Santafé, en 1778 -es decir seis años antes del proceso y la prisión-, Nariño escribe una carta a José Celestino Mutis en que menciona que con el motivo de tal nombramiento, "se me ha entorpecido el pensamiento que tenía de tener en casa una especie de tertulia..." 25

\section{Lecturas Ilustradas en el Campo}

Existen múltiples testimonios de que en los medios que hemos denominado ilustrados las prácticas de la lectura se habían modificado en algunos de sus aspectos. El intercambio constante de libros, la lectura colectiva de los textos -como en el caso del pequeño grupo de naturalistas de Popay án-, las nuevas formas de lectura en la soledad del campo, la lectura con ayuda de diccionarios para abrirse camino en la comprensión de los textos de las nuevas materias a las que se intentaba acceder, cierto cuidado en los juicios expresados sobre los textos leídos y un interés constante por hacerse a últimas ediciones y a traducciones cuidadosas, son índices de esas modificaciones.

Se encuentran en la correspondencia de los ilustrados huellas visibles de esos cambios, de los que podemos señalar algunos casos, apoyándonos, como ejemplo en parte de las cartas cruzadas entre el abogado y naturalista Joaquín Camacho y algunos de sus amigos y condiscípulos. Estas cartas tienen la particularidad de permitirnos observar la difusión de nuevas prácticas de lectura más allá de los medios propiamente urbanos, pues los corresponsales de Camacho en su mayoría habitaban haciendas, de las que eran propietarios. Existe aquí un elemento de gran originalidad, que no sabemos si se encuentra presente en los otros virreinatos hispanos: la constitución de prácticas societarias de tipo moderno podía darse por fuera de un marco institucional y simplemente apoyarse en relaciones tradicionales de amistad y de parentesco, sin que por

\section{la constitución de prácticas societarias de tipo moderno podía darse por fuera de un marco institucional $y$ simplemente apoyarse en relaciones tradicionales de amistad y de parentesco}

ello resulte menos claro su carácter de elemento fundador de una sociabilidad de libre "intercambio de ideas", lo que mostrará toda su significación al expresarse después de 1808 en el terreno de lo "público" y de la política.

Podemos empezar con algunas de las cartas que Joaquín Camacho intercambió con su amigo el abogado Miguel Tadeo Duran. Camacho tenía con él la experiencia de estudios comunes en el Colegio-universidad del Rosario, el interés por la lectura y por la investigación de la botánica, y se encontraban relativamente próximo, ya que Camacho era el corregidor de Pamplona, una población cercana a la región en que habitaba Gómez. Las cartas incluyen, como casi siempre ocurre con la correspondencia de los Ilustrados, aspectos muy variados: familiares, profesionales, sobre la situación política, noticias sobre amigos que se han visto o se han dejado de ver, sobre experimentación botánica, etc., pero aquí, de manera muy particular, noticias sobre las redes que en la región hacían circular los nuevos libros, sobre los tipos de lectura, sobre los autores apreciados, y sobre las propias formas de leer.

Así por ejemplo, en julio de 1803, Gómez Duran envía una carta a Camacho, en que

25 Carta del 15-1-1778, de Antonio Nariño, Archivo Nariño, op. cit, T. 2, pp. 72-73. 
le cuenta que "El Molina [Alfonso Molina, el filólogo español] y el Condorcet, ambas obras lasheleídoyaenmiviajeporSanGil...", pues este abogado lee durante sus viajes -práctica favorecida por los nuevos formatos de los libros- e incluye la compañía de libros en su valija. Enseguida agrega un juicio sobre una de las obras leídas, una exposición de las ideas de Condorcet, "que comprende las noticias de cosas tan útiles, que su lectura no me ha dejado más fruto que un deseo vivísimo de leer la obra original, por la que se hizo este análisis ${ }^{26 "}$.

En octubre de 1805, Gómez Duran le cuenta a Camacho que está dirigiendo "el Jovellanos" a su amigo Valenzuela -otro universitario que habitaba la región-, que ha recibido "el Condillac", y que se encuentra además pendiente de unos libros que ha encargado, de lo que le informará luego, "para que vea si le acomoda leer algunos ${ }^{27}$. Y días después empieza a hacer circular el nuevo libro de Jovellanos, enviándolo a otro de sus amigos, Valenzuela: "Por fin he remitido a nuestro amigo... el Informe sobre la ley agraria", pero agrega: "Queda copiado este libro", lo que nos confirma que la vieja práctica escolar de copiar los libros no desaparecía, aunque aquí el contexto anterior esta completamente modifi$\mathrm{cado}^{28}$.

Al parecer estas prácticas de lectura tienen una característica más: la de tratar de

26 Utilizo la obra de Rodríguez Plata, Horacio, La antigua provincia del Socorro y la Independencia, Bogotá, Biblioteca de Historia, Academia Colombiana de Historia, 1963. El subrayado es mió.

27 ídem, op. cit., p. 180.

28 ídem, op. cit., p. 183.

29 ídem, op. cit., p. 179.

30 Martínez Delgado, Luis,//oficiar biográfica delprocer Joaquín Camacho [y] documentos, Bogotá, Biblioteca Colombiana de Historia, Academia Colombiana de Historia, 1954, p. 186. Los libros se mandaban por correo con las cartas, pero también se usaba de trabajadores de la haciena, cfr. ídem, op. cit., p. 189.

31 ídem, op. cit, p. 195. Según una carta de 22-X-1804 Nieto recibió algunos de los libros a través de un mensajero, y se decide ahora a solicitar a Camacho el Orador perfecto; op. cit., idem, p. 195-196. establecer relaciones entre lo leído y lo observado. Ocurre que Gómez Duran no solo experimenta en su finca con el nuevo cultivo de la quina, sino que es un observador permanente durante sus viajes. Por ejemplo relata que al regreso de uno de tales viajes encontró una cabra, hija de venados, lo que le llamó la atención, para intentar un experimento sobre "si las terceras especies se reproducen", aunque confiesa no saber mucho de la materia, más allá "de lo poco que recuerdo del Buffon que leí en esa [Santafé]..."29.

Al mismo tiempo que con Gómez Duran, Camacho sostenía correspondencia con casi una docena de otros corresponsales de la región: por ejemplo con su pariente José Nepomuceno Nieto, quien por lo demás era también amigo y corresponsal de Gómez Duran. Nieto escribe a Camacho en octubre de 1803 diciéndole que agradece su deseo de instruirlo, "cuando me da la noticia de los libros que vienen" y que bien puede tomar para él los Viajes, y agrega que en cuanto a los "Elementos de medicina, estoy por observar el consejo de Baglivi, de leer solo en un libro de esta naturaleza, y este será el Culi en". A fin del mes le informa: "estoy atareado aprendiendo el idioma de Anacarsis, y así no omita mandarme sus Viajes $y$ avisarme su importe" ${ }^{130}$. En otra carta de agosto de 1804 Nieto menciona que se inclina a adquirir el Espíritu de Buffon, "el que me imagino la quinta esencia de la historia natural", aunque duda, pues no sabe si el texto será comprensible para un principiante "sin más ayuda que un diccionario. Usted me dirá su concepto para resolver". En cambio se ha decidido por el libro sobre La conquista de México, lo mismo que por El pirata de América, y encarga para un clérigo amigo suyo el libro de teología de Lárraga, "si es novísimamente ilustrado" ${ }^{31}$.

A principios de 1805 Camacho informa a su corresponsal que, como ya se encuentra en posesión de los libros, se dispone a diver- 


\section{Los efectos de la lectura, cuando existen, son complejos, en cierta manera "invisibles" por sí mismos, y se encuentran siempre incluidos en contextos mayores, de los cuales no resulta cómodo ni aconsejable separarlos}

tirse, "luego que me retire a las riberas del [Río] Niester, libre ya del ruido de los papeles del foro, que me tenía abrumado ${ }^{32}$. Así pues, lectura en soledad, en la casa de la hacienda a la orilla del río. Este retiro al campo para leer, que debe tener tanto de representación de la lectura, tomada de las propias lecturas, como de práctica efectiva, es una constante en gran parte de los Ilustrados, y se repite muchas veces, tanto en la correspondencia privada como en artículos de prensa ${ }^{3}$.

En la misma dirección van algunas de las cartas que a Joaquín Camacho dirigió el abogado Miguel Valenzuela, un hermano del botánico Eloy Valenzuela. Alumno de Camacho en el Colegio del Rosario, fue complicado en 1794 en los procesos contra los estudiantes; naturalista aficionado, ahora habitaba en la misma región, dividiendo su tiempo entre las actividades profesionales de jurista, la experimentación botánica y la lectura ${ }^{34}$. Al parecer los amigos corresponsales de la región no solo leen los mismos autores y los mismos libros de ciencias naturales, de viajes, de filosofía, sino que leen en los mismos ejemplares ${ }^{35}$ En mayo de 1807 Valenzuela cuenta a Camacho que ha recibido ya el primer tomo de Demóstenes y que remite un tomo más de Bomare; y al mes siguiente informa haber recibido un tomo del Viaje de Ciro, escribiendo que en San Juan de Girón "no hay obrita que sea nueva para vuestra merced", que Camacho podría buscar nuevos títulos en la ciudad que habita, Pamplona, con "los literatos aficionados, entre quienes pueden circular algunos". Y tal vez en relación con un reparo de su amigo, menciona que no olvida que debe regresar el libro de Jovellanos, "pero será aprendiéndolo de memoria", pues parece que a él también, como a Gómez y a los otros Ilustrados, los ha impresionado en alto grado el Informe sobre la ley •Jé agraria .

Se puede plantear la pregunta de cuáles podrían haber sido algunos de los efectos -culturales, sociales, personales- de este tipo de lecturas y de intercambio de libros y de correspondencia, pero no resulta fácil responder. Los efectos de la lectura, cuando existen, son complejos, en cierta manera "invisibles" por sí mismos, y se encuentran siempre incluidos en contextos mayores, de los cuales no resulta cómodo ni aconsejable separarlos ${ }^{37}$. Por lo pronto sabemos que la existencia de esta pequeña red de lectores no es un efecto directo de la lectura, puesto que los contactos eran anteriores y reposaban sobre orígenes regionales comunes, sobre relaciones familiares, sobre un pasado escolar común. Sin embargo las lecturas comunesy el intercambio epistolar

32 ídem, op. cit, p.199.

33 Cf. Por ejemplo Correo Curioso, El Ermitaño a los editores del Correo Curioso, No. 15, 26-V-1801.

34 Sobre la trayectoria escolar y profesional de Miguel Valenzuela cf. Archivo del Colegio del Rosario Vol 119, ff. 382-388.

35 Rodríguez Plata, H., La provincia del Socorro y la Independencia, op. cit., p. 298. La lectura en muchísimas ocasiones del mismo ejemplar, la espera de "turno" mientras uno de los amigos termina un tomo para continuar la lectura, la posesión de un comentario escrito en una carta, antes de disponer del libro, etc., se comprueban cruzando las informaciones de las cartas.

36 ídem, opc. cit., p.302

37 Cfr. al respecto R. Chartier y P. Bourdieu, "La lecture: una pratique culturelle", en Roger Chartier, editor, Pratiques de la lecture, op. cit., pp. 267-294. 
continuo deben haber dado más fuerza a esa comunidad social y deben haber dotado de una cierta homogeneidad cultural a los miembros de esa red, la cual, por lo demás, en este caso, nunca aparece asumida de manera consciente, como principio de organización. Pero es innegable reconocer en algunos de estos corresponsales un alto grado de compromiso con los ideales ilustrados -digamos, un cierto nivel de incorporación de tales ideales a la propia vida personal-, lo que se manifiesta por lo menos de dos maneras. Primero por la adquisición de un lenguaje, en el que se expresa sobre todo la idea de un tiempo histórico continuo, un movimiento que conduce las sociedades hacia el progreso, tiempo al cual la acción del hombre debe sumarse para acelerarlo. $\mathrm{Y}$ en segundo lugar por un intento de acercar sus "libros a la vida", de volver prácticas y reales esas concepciones que empezaban a ser las suyas. Los dos fenómenos están presentes sobre todo en las caitas de Miguel Tadeo Gómez Duran.

Una primera manifestación de ese cambio cultural, expresado en la vida personal se encuentra en una carta de Gómez Duran a Camacho, en la que le solicita que lo informe ("Si usted se tomase la molestia de instruirme") sobre la situación del corregimiento de Pamplona. Gómez Duran expresa su pregunta señalando los objetos precisos sobre los cuáles desea saber: se encuentra interesado en la extensión territorial del corregimiento, en los "renglones de la producción", en los "precios de los últimos cinco años", en los efectos que traería para la vida económica y social la apertura al comercio internacional, y en el estado

38 Rodríguez Plata, H., La provincia del Socorro y la Independencia, op. cit, p. 180-181.

39 Como se sabe, el absolutismo monárquico contenía elementos "protoliberales" que el liberalismo del siglo XIX en Hispanoamérica retomó de manera directa, pero sin permitirse reconocer la filiación ideológica, la cual, a mediados del nuevo siglo, no resultaba una referencia muy prudente, ni en relación con los oponentes políticos ni frente a lo que para ese entonces se llamará las "masas". Una observación de las rentas, todo expresado ya en el lenguaje de la economía moderna ${ }^{38}$. Se trata pues de una pequeña "encuesta" que dibuj a otros objetos que aquellos del estado de la "fabrica material de la iglesia", de la situación de las prácticas devotas, o de las intrigas en el vecindario.

Un segundo ejemplo lo proporcionan las reacciones de Gómez Duran frente a las medidas de desamortización de bienes de manos muertas, una medida que formará parte de las grandes discusiones del siglo XIX y que será un motivo de disputas y de inquietudes políticas y "espirituales" entre los republicanos. Para Gómez Duran, como para Camacho, la medida no plantea problemas: los bienes detenidos, inmovilizados, deben entrar en movimiento, deben pasar al mercado, deben permitir asociar el trabajo con la propiedad. Como sabemos, esta medida se empezó a ejecutar de manera muy parcial a finales del siglo XVIII, y se encontraba como propuesta en todos los tratados de economía de los Ilustrados españoles, particularmente en el Informe de Jovellanos sobre la ley agraria, que tanto admiraba Gómez Duran ${ }^{39}$. En una carta de Octubre de

Un segundo ejemplo lo proporcionan las reacciones de Gómez Duran frerite a las medidas de desamortización de bienes de manos muertas, una medida que formará parte de las grandes discusiones del siglo XIX y que será un motivo de disputas y de inquietudes políticas y "espirituales" entre los republicanos 
1805, Gómez Duran expresará su satisfacción por la noticia de que finalmente se procederá a "la enajenación de las fincas raíces que han caído en manos muertas", medida que le parece digna de un gobierno ilustrado (los ministros españoles y el Rey), pero de la que duda que se aplicará de manera decidida en Nueva Granada. Sin embargo considera que se ha dado un paso adelante y que ya existen esperanzas de que "los que vengan después de un siglo encuentren menos obstáculos para vivir del trabajo de sus brazos" 40

Al parecer Gómez Duran trató en varias ocasiones de hacer intervenir sus "lecturas", es decir, el nuevo punto de vista que iba adoptando sobre la sociedad, en su propia actividad de jurista, pues, en noviembre de 1807, en otra caita para Joaquín Camacho, y ante comentarios que se habían suscitado sobre algunas de las posiciones que en el "foro" había adoptado, le escribirá que, "Las Ordenanzas de los intendentes de México, las Leyes Indias, la doctrina de [Adam] Smith y del señor Jovellanos, son los fundamentos en que se apoyó mi dictamen"41. Así, sin que se puedan extraer conclusiones generales de ninguna especie, parece haber en este caso un intento de acercar "los libros a la vida", de volver práctica las lecturas realizadas en la soledad del Río Niester, de incorporar a la vida personal el ideal de la prosperidad y la creencia en el cambio de las sociedades, cuyos grandes obstáculos, de todas maneras, se reconocían, pues, por ejemplo, en una carta muy anterior, de 1802 , en que Gómez Duran lamenta la probable desaparición del Correo Curioso, el periódico de Santafé en ese año, por ausencia de un número suficiente de suscriptores, escribirá que el suceso

"me ha hecho ver claramente el espacio inmenso que separa la actual generación de aquella que en el orden invariable de las cosas ha de tocar el punto de felicidad a donde naturalmente conduce el progreso de las luces"

Esta singular experiencia de libros y lectores en la provincia del Socorro, entre hacendados, funcionarios y abogados (todos notables urbanos, pero vinculados al campo), debe estar relacionada con diversas clases de fenómenos ${ }^{43}$, el más importante de los cuales, desde luego, la formación universitaria y el relativo incremento del mercado de un tipo de libro por el cual existía interés. Se puede recordar que la región envió durante todo el siglo XVIII, sobre todo después de 1770, escolares a estudiar a Santafé, y que después de 1780 los vecindarios demostraron interés por

\section{hubo durante todo el siglo XVIII la presencia constante de preceptores privados y "maestros ambulantes" que hicieron que el fenómeno del analfabetismofuera menor que en otras regiones de Nueva Granada}

precisa sobre este punto, en el caso de Nueva Granada, en Saffbrd, Frank, El ideal de lo práctico, Bogotá, El Ancora editores, 1989, p. 36.

40 Rodríguez Plata, H. La provincia del Socorro y la Independencia, op. cit., ídem.

41 ídem, op. cit., p. 181. Para la misma posición en Joaquín Camacho, cf. Martínez Delgado, L., Biografía del procer Joaquín Camacho, op. cit., p. 115. Para el caso de Camilo Torres, véase Carta del 6-III-1808 para José Antonio Pérez de Valencia, en Popayán, y Carta del 19-111-1808 para Santiago Arroyo, en Repertorio Colombiano, Wo $\backslash 18$, No. 1,1898, pp. 10-11 урp. 15-17.

42 ídem, op. cit., pp. 176-177. El lenguaje es aquí inequívoco en cuanto a su filiación.

43 Sobre el siglo XVIII en la región cf. Phelan, John, el Pueblo y el Rey, Bogotá, Carlos Valencia editores, 1980, y sobre la sociedad y economía del siglo XIX en la región Nieto Arteta, Luis Eduardo, Economía y cultura en la historia de Colombia, Bogotá, Tercer Mundo editores, 1963, y Johnson, David, Santander: Cambios sociales y económicos. Siglo XIX, Bogotá Carlos Valencia editores, 1983. 
1805, Gómez Duran expresará su satisfacción por la noticia de que finalmente se procederá a "la enajenación de las fincas raíces que han caído en manos muertas", medida que le parece digna de un gobierno ilustrado (los ministros españoles y el Rey), pero de la que duda que se aplicará de manera decidida en Nueva Granada. Sin embargo considera que se ha dado un paso adelante y que ya existen esperanzas de que "los que vengan después de un siglo encuentren menos obstáculos para vivir del trabajo de sus brazos" 40

Al parecer Gómez Duran trató en varias ocasiones de hacer intervenir sus "lecturas", es decir, el nuevo punto de vista que iba adoptando sobre la sociedad, en su propia actividad de jurista, pues, en noviembre de 1807 , en otra caita para Joaquín Camacho, y ante comentarios que se habían suscitado sobre algunas de las posiciones que en el "foro" había adoptado, le escribirá que, "Las Ordenanzas de los intendentes de México, las Leyes Indias, la doctrina de [Adam] Smith y del señor Jovellanos, son los fundamentos en que se apoyó mi dictamen"41. Así, sin que se puedan extraer conclusiones generales de ninguna especie, parece haber en este caso un intento de acercar "los libros a la vida", de volver práctica las lecturas realizadas en la soledad del Río Niester, de incorporar a la vida personal el ideal de la prosperidad y la creencia en el cambio de las sociedades, cuyos grandes obstáculos, de todas maneras, se reconocían, pues, por ejemplo, en una carta muy anterior, de 1802, en que Gómez Duran lamenta la probable desaparición del Correo Curioso, el periódico de Santafé en ese año, por ausencia de un número suficiente de suscriptores, escribirá que el suceso

"me ha hecho ver claramente el espacio inmenso que separa la actual generación de aquella que en el orden invariable de las cosas ha de tocar el punto de felicidad a donde naturalmente conduce el progreso de las luces"

Esta singular experiencia de libros y lectores en la provincia del Socorro, entre hacendados, funcionarios y abogados (todos notables urbanos, pero vinculados al campo), debe estar relacionada con diversas clases de fenómenos ${ }^{43}$, el más importante de los cuales, desde luego, la formación universitaria y el relativo incremento del mercado de un tipo de libro por el cual existía interés. Se puede recordar que la región envió durante todo el siglo XVIII, sobre todo después de 1770 , escolares a estudiar a Santafé, y que después de 1780 los vecindarios demostraron interés por

\section{hubo durante todo el siglo XVIII la presencia constante de preceptores privados $y$ "maestros ambulantes" que hicieron que el fenómeno del analfabetismo fuera menor que en otras regiones de Nueva Granada}

precisa sobre este punto, en el caso de Nueva Granada, en Safford, Frank, El ideal de lo práctico, Bogotá, El Ancora editores, 1989, p. 36.

40 Rodríguez Plata, H. La provincia del Socorro y la Independencia, op. cit., ídem.

41 ídem, op. cit., p. 181. Para la misma posición en Joaquín Camacho, cf. Martínez Delgado, L., Biografía del procer Joaquín Camacho, op. cit., p. 115. Para el caso de Camilo Torres, véase Carta del 6-III-1808 para José Antonio Pérez de Valencia, en Popayán, y Carta del 19-111-1808 para Santiago Arroyo, en Re pertorio Colombiano, $\downarrow \backslash$. 18, No. 1,1898, pp. 10-11 ypp. 15-17.

42 ídem, op. cit., pp. 176-177. El lenguaje es aquí inequívoco en cuanto a su filiación.

43 Sobre el siglo XVIII en la región cf. Phelan, John, el Pueblo y el Rey, Bogotá, Carlos Valencia editores, 1980, y sobre la sociedad y economía del siglo XDC en la región Nieto Arteta, Luis Eduardo, Economía y cultura en la historia de Colombia, Bogotá, Tercer Mundo editores, 1963, y Johnson, David, Santander: Cambios sociales y económicos. Siglo XIX, Bogotá Carlos Valencia editores, 1983. 
la fundación de aulas de latinidad y humanidades, de las que casi siempre fueron maestros antiguos universitarios de Santafé. Pero más allá de las fundaciones escolares, hubo durante todo el siglo XVIII la presencia constante de preceptores privados y "maestros ambulantes" que hicieron que el fenómeno del analfabetismo fuera menor que en otras regiones de Nueva Granada, según indican muchos testi- 44 momos .

Es curioso que Joaquín de Finestrad, el autor de El Vasallo Instruido, intente explicar la Revolución de los Comuneros (1781) por el "estado de opinión" en la región y por la desafección hacia el Rey ("se hablaba mal de la persona del Rey"), lo que a su vez explicaba por la presencia de "libros y autores disolventes":

"Erafirme mi creencia de que te-

nían asiento en estas remotas regiones el

barón de Pufendorf, en su Derecho de

Naturalezay de Gentes... Hugo Grotio en

su Derecho de Bellis y Pacis, Thomas

Hobbes, Wolfio... el francés Raynal y el

escocés Robertson, extranjeros los más celebrados que escribieron con poco respecto contra la religión y el sometimiento..

Es difícil saber si Finestrad, quien mezcla autores bien disímiles y supone relaciones directas entre leer un libro y levantarse en armas, tuviera razón ${ }^{46}$. Lo que sí debe resultar cierto es que en la región los niveles de lectura eran mayores que en buena parte del virreina-

44 Cf. Silva, R., Universidad y sociedad, Bogotá, Banco de la República, 1992, pp. 191 y 344.

45 Cf. El Vasallo instruido en el estado del Nuevo Reino de Granada, y en sus respectivas obligaciones. Instrucciones que ofrece a los literatos y curiosos el Reverendo Padre Joaquín de Finestrad... Cartagena de Indias, 1789, en B. N., Sala de R y C, mns. El comentario en Silva, R. "La reoría del poder divino de los reyes en Nueva Granada: Una nueva lectura del 'Vasallo Instruido' de Joaquín de Finestrad", en: Dos estudios de Historia Cultural, Cali, CIDSE/ Universidad del Valle, 1993.

46 Para matizar este punto de vista parcial, cfr. Phelan, J., El Pueblo y el Rey, op. cit, p. 15 to, como lo muestran los testimonios que hemos citado de este grupo de hacendados.

\section{La Lectura de Gacetas}

A finales del siglo XVIII y principios del siglo XIX, la "gaceta" se convierte, sea como órgano de información científica, sea como medio de información política, en un instrumento indispensable de la formación cultural de los Ilustrados. Pero un instrumento que, al mismo tiempo, transformará de manera grande sus prácticas de lectura y sus hábitos de información, y contribuirá en alto grado a acercarlos a la actualidad del mundo. El cónsul sueco en Cádiz, Gustav Gahn, recomendaba a su amigo el botánico J. C. Mutis, suscribirse a lo que él llamaba en sus caitas los "jornales europeos". Según la definición que Antonio Nariño hacía de las actividades de lectura en la sociedad que había creado, las lecturas esencialmente recomendadas eran las de "diarios" y "periódicos". La propia prensa local, por su parte -y era normal- realizó una alta valoración del significado cultural de la prensa y del periodismo, y por momentos los presentó como el sustituto mismo de la educación formal, cuando ésta no existía o no

\section{A finales del siglo XVIIIy principios del siglo $X I X$, la "gaceta" se convierte, sea como órgano de información científica, sea comomedio de información política, en un instrumento indispensable de la formación cultural de los Ilustrados}


cubría a toda la población. Así lo hizo por ejemplo, el Papel Periódico en la propia presentación de sus tareas (pero también lo hicieron otros "papeles públicos" similares en otros virreinatos, como El Mercurio Peruano ${ }^{4 t}$.

Como se sabe, el tema de la importancia de los "papeles públicos" fue común a todos los "movimientos ilustrados" del continente, y bajo su sentido inmediato de informarse, conocer, ilustrarse, recubre dos temas mayores de la sociedad moderna, y una diferencia radical con el modelo cultural de las sociedades de antiguo régimen: en principio el tema de la libertad de información y de lectura, y un poco más allá el tema de la libertad de escribir, dos problemas cruciales de todas las sociedades contemporáneas. Sin embargo por el momento se trata aquí tan solo de insistir en el aumento, en el último cuarto de siglo y sobre todo después de 1800, del número de gacetas que se conocía en Nueva Granada y en la multiplicación de los títulos de las gacetas a las que se podía acceder, lo mismo que de subrayar las formas bajo las cuales un ejemplar "viajaba", y podía ser el objeto de lectura por múltiples sujetos en distintos puntos, lo mismo que objeto de copia de partes de sus artículos.

A parecer, a principios del siglo XIX los niveles locales de información sobre lo que acontecía en el mundo eran mayores, había cierto gusto por la lectura de lo que hoy en día llamaríamos la prensa, y los intereses de lectura se habían ido desplazando del lado de las ciencias al lado de la política. Sin embargo, aquí también el fenómeno parece limitado al círculo de los lectores ilustrados, aunque esta impresión puede ser, en parte, un efecto de distorsión producido por los propios testimonios con los que contamos. En la correspondencia del botánico José Celestino Mutis ha quedado huella visible de ese contacto con las gacetas (más allá de la presencia en su biblioteca de "anales" y "joumaux des savants", que constituyen todavía una forma de libro).

Por ejemplo, al Director de Minas del virreinato de Nueva Granada, Juan José D'Elhuyar, Mutis escribe en una corta nota que ha llegado el "correo marítimo" (es decir un buque de España) y "por consiguiente las gacetas", indicando así que en la vida cotidiana y a es comente la asociación entre la llegada de buques y disponer de gacetas que vienen de Europa. Mutis describe luego lo que puede ser una de sus formas de lectura de una gaceta, pues señala que las envía "sin haberlas visto más que por encima, como siempre lo ejercito", y pasa a comentar una de las noticias encontradas (una noticia científica sobre el método de tratamiento de minerales de Born, problema sobre el cual trabajaba en ese momento D'Elhuyar), aunque agrega, con gesto desconfiado, que "puede ser noticia gacetal". En todo caso, las gacetas parten pronto, pues, "despacho al mozo inmediatamente, acompañando otra [gaceta] de México"48. Encontramos otro ejemplo en una carta muy posterior con la que Mutis remite al D'Elhuyar "las últimas gacetas", las que D'Elhuyar deberá leer "mientras yo concluyo las primeras" ${ }^{49}$, y cierra la carta con una breve frase sobre política internacional, obtenida a partir de una de las noticias leídas.

La correspondencia de Mutis con el "comerciante ilustrado" José Ignacio de Pombo, quien residía cerca del puerto de Cartagena de Indias -lugar de entrada de impresos y libros-, da testimonio de los mismos mecanismos, y

47 Con ocasión de la aparición de el Mercurio Peruano, el Papel Periódico escribía: "Y quién podrá negar que tales escritos tienen el mayor influjo sobre la pública educación? Ningún otro medio podía haberse inventado más fácil y oportuno para ilustrar al común de los hombres... ellos han abierto el camino a la pública ilustración...". PapelPeriódico, No. 24, 22-VII-1791.

48 Carta del 12-VII-1785, Archivo epistolar del sabio naturalista don José Celestino Mutis, edición de Guillermo Hernández de Alba. Bogotá, Editorial Kelly, 1968, T. Y, pp. 240-241.

49 Carta del 1-II-1789, Arch epist, op. cit, T. 1, pp 447-448. 


\section{Este punto de la velocidad de las comunicaciones resultará fundamental cuando estalle la crisis política de 1808 , sobre la que los neogranadinos no leerán de manera continua, día a día, sino de manera discontinua y concentrada -y a veces disparatada- corno efecto de avatares insalvables del viaje marino y la escala en puertos intermedios.}

de algunos otros más. Esta correspondencia, frecuente sobre todo a partir de 1800, muestra la importancia creciente que va tomando el periodismo para los Ilustrados, y la multiplicación de la velocidad de su llegada. Así por ejemplo, Pombo le dirá en carta del 30 de diciembre, que le incluye dos impresos -no sabemos cuáles-, y que con la llegada del buque -en que venía de Estados Unidos su socio comercial- disponen de "noticias y gacetas inglesas hasta de 18 de octubre sobre

50 Sobre este punto cf. Guerra, F-X, Modernidade Independencias, op. cit, p. 129. La situación de desigualdad ante la información política de coyuntura se reproduce memamente, pues los puertos se informan antes que el interior del territorio, y dentro del interior, primero las ciudades que el campo.

51 Carta del 30-VIII-1803, Arch. epist, op. cit., T. 3, p. 113. Pero la gaceta sigue funcionando también como catálogo de "librería". Así por ejemplo, en carta del 20-VI-1807, Pombo enviará a Mutis "una nota de las obras que se imprimirán de nuestro Humboldt, sacada de un periódico literario ingles de 1805, y que ya deben haberse publicado", p. 173.

52 Cf. por ejemplo Cartas del 20-XII-1803 de Pombo, Arch. epist., T. 3, y Carta del 30-XII-1805, idem, pp. 148-149.
Europa", es decir que, a principios de siglo, los granadinos se encuentran leyendo las noticias de España y Europa con un retraso aproximado de tres meses.

Este punto de la velocidad de las comunicaciones resultará fundamental cuando estalle la crisis política de 1808 , sobre la que los neogranadinos no leerán de manera continua, día a día, sino de manera discontinua y concentrada -y a veces disparatada- como efecto de avatares insalvables del viaje marino y la escala en puertos intermedios. De tal suerte que en ocasiones se conoce una decisión, antes que se conozcan las condiciones que la produjeron; o se discute sobre una medida adoptada en España, cuando la siguiente y a se encuentra en marcha; o se preparan elecciones para órganos recientemente creados, que la velocidad de los sucesos ya ha hecho desaparecer, etc. Todo lo cual, en tiempos de cambio acelerado de la política, le otorga a ésta mucha más incertidumbre de la que de por sí inevitablemente conlleva, y acreciente el peso del rumor y de lo que se supone ha debido ocurrir ${ }^{50}$.

En cuanto a las prácticas de lectura, casi siempre asociadas a las prácticas de escritu$r a$, las cartas de Pombo son ejemplares para mostrar el uso que se hacía de las gacetas -como en parte hizo también con los libros-. Así es como Pombo resume en muchas cartas el contenido de las gacetas, pero a veces directamente las copia él, o las hace copiar por medio de sus "secretarios": por ejemplo un artículo de El Correo Mercantil que envía a Mutis, "por si no tenía noticia de ello" ${ }^{51}$. Dos hechos se van haciendo particularmente notables en las cartas de Pombo a Mutis, leídas desde el punto de vista de la "información". De una parte la amplitud que va tomando la comunicación de noticias, pues Pombo menciona gacetas de Madrid, de Berlín, de París, de la Habana, en otros lugares ${ }^{52}$, pero igualmente se va abriendo un frente de noticias que parece conectar ahora de manera más orgánica 
con los Estados Unidos, pues Pombo comienza a recibir de manera constante gacetas científicas y políticas desde la América del Norte $^{53}$. De otra parte el peso que la información política va tomando un poco antes de la crisis de 1808. En el caso de Pombo las menciones son repetidas desde $1803^{54}$, pero se encuentran también presentes en las cartas de los letrados de la Provincia del Socorro. Así por ejemplo, en 1807, Miguel Valenzuela escribirá a Joaquín $\mathrm{C}$ amacho:

"A vuestra merced han escrito haber acabado su carrera el héroe francés, y por aqui han corrido noticias de que intenta agregar a su imperio la parte antigua de España hasta elEbro... " .

Este paso de la lectura de la gaceta de carácter científico o de divulgación de la ciencia a la lectura de un periodismo de carácter político -el que será dominante en el siglo XIX colombiano- no es, desde luego, un efecto ni directo ni exclusivo de las gacetas y de sus informaciones, sino la expresión de un proceso de cambio más general que se encuentra en marcha en la sociedad.

Pero es característico de esa transformación en Nueva Granada, el que los cambios no logren expresarse ni de manera fácil ni de manera clara, en razón del ambiente de miedo y de represión en que son vividos. En el caso de los "papeles públicos", una de las primeras disposiciones que tomaron las autoridades, cuando apareció la pequeña edición de Los Derechos del Hombre (1794), fue la de enviar

53 Cf. Por ejemplo Carta del 10-111-1806,/4rc/i. epist., T. 3, p. 153.

54 Cf. Por ejemplo carta del 19-IX-1803, Arch. epist., op. cit, T. 3. Pp. 115-116., en que comenta a Mutis, desde luego con tardanza, la situación política francesa, lamentando al final de la carta que "se ha depuesto el inapreciable [uso del] nombre de ciudadano". P. 116. comunicaciones a las autoridades para que se informaran

"de los sujetos que tengan correspondencia en esta capital, principalmente con motivo de los papeles públicos que se imprimen en ella y se remiten por el coireo... que se procure saber si con dichos periódicos o de otro modo se ha dirigido el impreso perjudicial, recogiéndolo en caso de ser hallado, con las copias que puedan haberse sacado...

Así pues, la época del florecimiento de los "papeles públicos", de la prensa cotidiana, del periodismo político, ha tenido que esperar condiciones favorables hasta los años posteriores a la crisis de 1808 , pero, en el momento de su aparición, una transformación mayor se hará visible, pues ya no se dirá de los "papeles públicos" simplemente que son un "medio de ilustración y de educación", sino que se dirán que son la forma por excelencia de "fijar la opinión", un rasgo distintivo del mundo moderno que se anunciaba, y de otra configuración de lo que desde entonces llamamos "lo público". Antonio Nariño lo escribía en uno de los primeros números de su periódico $L a$ Bagatela, en la "Carta a un amigo":

"Tu sabes que es imposible propagar la instruccióny fijar la opinión pública sin papeles periódicos, que siendo cortos y comenzando a rodar sobre las mesas, obligan en cierto modo a que se i, 58. lean
55 Martínez Delgado, L., Noticia biográfica del procer Joaquín Camacho, op. cit., p. 298.

56 Sobre el carácter general del proceso para todo el mundo hispánico cf. Guerra, F-X, Modernidad e independencias, op. cit., p. 36 y ss, pp. 42-50, y 50-54.

57 Procesos, op. cti., p. 174.

58 La Bagatela, Suplemento del No. 4, 4-VIII-1811 